Ophthalmic Hospital, and as President of the Ophthalmological Society of the United Kingdom, he has been and is intimately concerned with the teaching of ophthalmology to undergraduate and post-graduate students, and with the qualifications which are indubitably requisite in applicants for the position of ophthalmic surgeon to hospitals and infirmaries and for ophthalmic posts under the Ministry of Health, the Board of Education, and the County Councils. The votes of Fellows of the College who are ophthalmic surgeons will not alone suffice to secure Mr. Fisher's election, and it is to be hoped that other voters will recognize the importance of securing the due representation of ophthalmology on the Council.

\title{
The Guild of Blind Gardeners
}

The letter which we publish in this issue under the signature of Mrs. Adolphus Duncombe, is one which is sure to command the sympathetic attention of ophthalmic surgeons. Mrs. Duncombe is a lady well known in London society, and is another illustration of the magnificent courage with which men and women, who having lost their sight after many years of the fullest enjoyment of it, have refused to bow to misfortune and determine instead to spend themselves in the service of those to whom life has offered fewer alleviations when overtaken by the disaster of blindness. A keen gardener in former days, she has drafted a scheme for a School of Gardening and Farming for the Blind, and has enlisted the services of a number of well known people, including several ophthalmic surgeons. "The object of the Guild is to encourage the blind to undertake gardening as a healthy and interesting occupation in addition to any sedentary work they may be engaged in," as well as to fit those, who desire to do so, to earn a living thereby. Mrs. Duncombe and her colleagues are most anxious to get into full touch with ophthalmic surgeons and other medical men, whose work brings them into contact with the class of people in whose interests this work is undertaken.

\section{ABSTRACTS}

\section{I.- $\overline{\text { MYOPIA }}$}

Edridge-Green, F. W.-On the cause and prevention of myopia. Lancet, March 5, $192 \mathrm{I}$.

In his Arris and Gale Lecture, Edridge-Green re-states, and in some respects amplifies, the argument originally published in the 
Lancet, January 26, 1918, that the cause of acquired myopia is not pressure on the eyeball brought about by near work, but raised intraocular pressure, the result of physical effort, such pressure acting upon the weak point of the sclera about the optic nerve. Special liability of the sclera to give way under pressure or to be affected by certain diseases may be hereditary, but one gathers that in the author's opinion, this is the sole influence of heredity in the causation of myopia.

The statement is made that "it is very doubtful whether the use of the eyes for near work has anything to do with the production of myopia." This, taken in conjunction with another statement (vide infra) that the author does not believe myopia is increased by near work, and with the use of the singular number of the word "cause" in the title, seems to justify the assumption that he is out for the complete overthrow of the older views in favour of a different and sole cause of the disease. The argument, therefore, can be divided into two parts : destructive and constructive. While contending that Edridge-Green has not succeeded in establishing his constructive argument, namely, that raised intraocular pressure is the sole cause of myopia, the reviewer considers that he has produced a considerable body of evidence in this and his previous communication in favour of it as one cause of the disease.

Let us first examine the destructive argument.

(1) "The detailed examination of some thousands of cases of myopia fail to convince me that in a single case myopia had been either caused or increased by the use of the eyes for near work." This statement advances no proof.

(2) "Arnold Lawson showed 5 per cent. higher myopia in the better lighted and ventilated school of Aldenham and St. Jude's schools." This is a quotation from the "American Encyclopedia of Ophthalmology," which certainly represents a statement of ascertained fact, although the statement is incorrectly transcribed, and the exact meaning, as the sentence stands, has to be guessed,

(3) From a leading article in the British Medical Journal, "We believe that myopia is neither originated nor increased by near work." That is merely the opinion of the anonymous writer of the article.

(4). "Ernest Thompson gives the following figures on the incidence of myopia in Lanarkshire : urban districts, 17 per cent.; rural districts, 20.5 per cent.; mining, agricultural, and manufacturing districts, 26 per cent." Ernest Thomson never made such a wide statement at all. He said, referring to these and other figures, "They show that in so far as concerns the children in the County of Lanark who apply for treatment under the voluntary scheme of the Education Authority, those attending rural schools 
present a higher percentage of myopia and myopic astigmatism in one or both eyes than those attending urban schools." "The italics occur in the original, and were meant definitely to show that only defective sighted children applying for treatment were under consideration. To refer to these figures as showing "the incidence of myopia in Lanarkshire" is absurd and somewhat careless.

(5) "Quite apart from mechanical difficulties which the convergence hypothesis presents, we find that in convergence excess, as in convergent strabismus or internal squint, myopia is not produced, and convergent strabismus is almost exclusively found in hypermetropic eyes." The answer to this is that the statement is incorrect. Without prejudice to the argument as to the causation of myopia by convergence excess, it is perfectly certain that, in children, convergent squint and esophoria are frequently associated with myopia and myopic astigmatism. In children - and are not children our principal care in this disease-these conditions of muscular imbalance are not "almost exclusively found in hypermetropic eyes." The reviewer holds no brief for any one cause of myopia, but is under the impression that he has definitely disproved Edridge-Green's statement (British Journal of Ophthalmology, July, 1919).

(6) "Again, many children become myopic without having used their eyes particularly for near work, especially when very young." This is true, and it is almost the only strong statement of fact which the author has brought against the near work theory.

The near work hypothesis may or may not be a sound one, but it does not seem to have suffered much from Edridge-Green's attack.

After one has read the constructive portion of the argument, that raised intraocular pressure acting on a weak sclerotic is the cause of this disease, one has to ask one's self "Is this proved ?" The reviewer suggests that the answer must be "No! The evidence is insufficient." Nevertheless, raised intra-ocular pressure as $a$ cause is very interesting. Put briefly, the theory as set out by EdridgeGreen is as follows:- Owing to heredity there may be a "special weakness of the sclerotic to give way under pressure or to become affected by certain diseases." (The author also suggests that the anatomical arrangements for the prevention of the distension of the eye may be defective.) The directly exciting causes are such diseases as measles, whooping cough, and bronchitis. The author holds that the influence of measles is clear and definite, and leans to the view that it produces sclerotic softening. Whooping cough and bronchitis may act by increasing intraocular pressure. The lifting of heavy weights does the same thing. Although it is not definitely so stated in this lecture, one gathers that many such cases are known to the author, and indeed, some of them are related in his 
article in the Lancet of January 26, 1918. But it occurs to one to ask whether such cases were not mainly adolescents and adults when examined, and whether the author has sufficiently accounted for myopic children.

Edridge-Green then discusses the mechanics of the raised pressure, making reference to the works of Priestley Smith, of Henderson and Starling, and of Hill and Flack. "It will be noticed," he says, "that the intraocular pressure rises both when the arterial pressure is increased and when the capillary-venous pressure is increased. Whether the eye will stretch or not when both occur together depends upon the power of the sclerotic to resist the increased pressure. When this is sufficient myopia will not be produced." Again, "the obstruction to the posterior lymph channels appears to be the chief cause in the production of myopia."

The following specific case cited by the author is certainly a strong one, provided all the facts stated to him are correct. " $A$ man staying at a farm had to help to hold a bull which had become wild, and he had to exert his strength to the utmost; he ruptured himself, became myopic to a low degree and blind in one eye through detachment of the retina in the one afternoon; he stated that he had previously very good sight."

If one wishes to be critical of such cases in adults one will naturally suggest that possibly all the facts of the previous history are not correctly known. A patient's statement as to the previous condition of his sight does not constitute a proof.

The author next passes on to the prevention of myopia. This is on the lines one would expect, namely, the avoidance of use of the eyes in a stooping posture, good light, hygienic surroundings, and so on. These orthodox procedures are "advisable," the author says, "but they do not seem to produce much effect in the prevention of myopia." Further, it is necessary to be careful during convalescence after those illnesses which produce myopia and when there is an hereditary tendency to myopia, to avoid postures and exercises which may cause raised intraocular pressure. Exercises which cause a feeling of pain or tension in the eyes should be strictly forbidden. "All exercises should be performed as far as possible in the erect position, with the eyes pointing forward."

Most of the above advice and much more offered by the author to those in charge of children and to energetic adolescents, might be given by any ophthalmic surgeon to a myope, but the heading of this section of the article is "Prevention of Myopia." The prevention of myopia and the prevention of the increase of already diagnosed myopia are, in practice, two different problems which the reviewer does not think the author has clearly separated in this lecture. With regard to the problem of the prevention of increase of myopia in the school child by optical correction and regulation of 
near work, the author, except for the caution against stooping, has not a word to say. That is natural, since he denies the influence of near work on myopia. Racial incidence, the tendency to sex limitation, the cessation of extension under suitable optical correction and regulation of education have all been left severely alone by Edridge-Green, for none of them would have helped to prove the correctness of his theory of raised intraocular pressure as the sole cause of myopia. The second-named would have told against it.

It is the opinion of the reviewer then, that while some interesting clinical facts have been brought forward which point to increased intraocular pressure, possibly associated with heredity, as a cause of myopia or its increase, no sufficient argument has emerged for discarding our older views or for setting up a new hypothesis to rule our treatment of all cases of myopia.

ERNEST THOMSON.

\section{II-NIGHT-BLINDNESS AT THE FRONT}

(I) Birch-Hirschfeld, A. (Königsberg).-Night-blindness at the Front. (Nachtblindheit im Felde.) Bericht der Ophthal. Gesellschaft, Heidelberg, 1916.

(1) Birch-Hirschfeld reports on a series of 155 cases which had come under his notice up to 1916 ; in 120 of these night-blindness had existed before the war, while in 35 it only developed during active service.

In 49 cases of this series the central vision was markedly defective.

The fundi in 73 cases were normal: 34 showed a marked deficiency in pigmentation, while in 41 there were slight changes in the pigmentation similar to those described by Augstein. The author, however, was unable to attach much significance for either aetiology or diagnosis to these changes.

Examination of the visual field revealed in a large number of his cases a contraction, especially for blue, in diminished light-this point, in fact, was of much use as a help in the diagnosis of this affection.

For determining the stimulus-threshold and the adaptation, he rejected as unsuitable the watch with illuminated figures that was in common use, but employed an adaptometer devised by himself. $\mathrm{He}$ found that in the great majority of his cases the stimulus-threshold was raised and the adaptation at the same time reduced.

As to prognosis, it was difficult to estimate this, as in only 54 was 
he able to watch the progress of the case for some time; of these only 10 showed improvement.

The aetiology of this disease depends on various factors, general or local-hereditary influences, errors of refraction (especially myopia), general debility through lack of proper nourishment, diseases of the liver and intestines, loss of blood from wounds, toxic substances (quinine, optochin, and perhaps alcohol), nervous disturbances. Exposure to bright light only occasionally acts as an exciting cause where a predisposition to the disease exists. $\mathrm{He}$ would attach importance to the war as a causative factor only in so far as the conditions under which it was waged emphasized the seriousness of this affection.

The author rejects the theory that night-blindness is a form of neurasthenia, and comes to the conclusion that night-blindness is due to an organic disturbance in that apparatus in the retina with which is associated a change in sensibility in the dark.

ThOMAS SNOWBALL.

(2) Löhlein, W. (Greifswald), - Observations upon nightblindness at the Front. (Beobachtungen uiber Nachtblindheit im Felde.) Bericht der Ophthal. Gesellschaft, Heidelberg, 1916.

(2) The conclusions to which Löhlein comes as a result of his experience on the Western Front are summed up as follows :-

In about half of the cases of so-called night-blindness at the Front, examination under certain precautions shows that the visual disturbances at night are not, or not essentially, due to a diminution in dark adaptation.

If, however, the number of such cases is very high, it is not necessary to assume that they are a special product of the war: it is due to the fact that in these individuals defective adaptation had previously existed, but was only brought into prominence by the increased demands made on them in night fighting.

Thomas SNowball.

(3) Jess, J. (Giessen).-Researches in night-blindness at the Front. (Die Untersuchung auf Nachtblindheit an der Front.) Bericht der Ophthal. Gesellschaft, Heidelberg, 1916.

(3) For the diagnosis of true night-blindness, Jess attaches great value to the careful estimation of the visual field where the conditions for examination, as in a field hospital, are not favourable for testing the adaptation; this method has also the advantage of being less liable to error through malingering.

In testing the colour sense, he insists on the necessity of mapping 
out the field for yellow 'as well as those for blue, red, and green. $\mathrm{He}$ found that in a considerable number of cases of acquired or congenital night-blindness, the field for blue was not diminished, while that for yellow was contracted within the limit for red and in places touched that for green; in more marked cases the blue was contracted to within red and was named green; after treatment the field for all colours, but especially for yellow, was increased in three of his cases.

This inversion of the fields for red and yellow, which is illustrated by a number of charts, very quickly demonstrated the presence of night-blindness.

Defects in the field of the character of peripheral ring scotomacomparable to those observed after exposure to bright light in airmen-were found in seven cases.

Thos. SNowball.

\section{III-OPERATIONS}

(I) Teulières and Ourgaud.-A case of pedicled corneal graft. (Sur un cas de greffe cornéenne à pédicule.) Arch. d'Ophtal., March-April, 1917.

(1) The authors report, with full clinical details, the case of a soldier whose right eye was wounded by a fragment of a shell on October 24, 1916. He did not come under the care of Drs. Teulières and Ourgaud until November 21. The missile had cut a large tongue-shaped transverse flap across the middle of the cornea, which remained attached by its base at the limbus on the nasal side. It measured about $6 \mathrm{~mm}$. from base to tip and $3 \mathrm{~mm}$. vertically. The flap included, as well as could be judged, about half the thickness of the cornea. It was freely movable, except at its pedicle. The wound having occurred 28 days previously, the flap was completely opaque and was thickened by infiltration. The surface of the cornea from which the flap had been separated was somewhat opalescent but showed no sign of infection. The flap was carefully replaced and the whole cornea accurately and firmly covered by conjunctiva which, divided at the limbus in its whole circumference, was brought forward and well sutured over the cornea. Argyrol was instilled and both eyes were bandaged. When the conjunctiva retracted the flap had become firmly adherent. It projected slightly above the surrounding cornea : it slowly became less opaque, clearing from the base toward the apex. In February, 1917, there was no 
prominence, and the whole area of the flap had cleared considerably. V. was $1 / 25$.

The report is illustrated by three drawings, which in themselves describe the case adequately.

J. B. LAWFORD.

(2) Martin, H. (Almeria)-Papillary ectasia and lumbar puncture. (Ectasie papillaire et ponction lumbaire.) La Clin. Ophtal., July, $191 \%$.

(2) Martin describes and discusses three cases of papillary oedema with more or less complete blindness in the treatment of which lumbar puncture was the chief factor. All three cases were diagnosed as due to chronic tuberculous meningitis of the base which secondarily brought about the ocular condition by increase of intracranial pressure from excess of cerebro-spinal fluid. The first case. a woman, married, aged 29 years, blind in both eyes, the left blind for four years, had lumbar puncture three times and ended up with the left eye blind, the right eye having acuity of $1 / 3$. The left disc was atrophic, the right almost normal. The second case, a woman of 26 years, was particularly stubborn and lumbar puncture was done fifteen times, from 20 to 25 cubic centimetres being removed on each occasion. This patient eventually had visual acuity $1 / 6$, slight atrophy of the discs, increased size of veins and diminution of the arteries. The third case, in a girl of 16 years, was the most successful. When first seen there were mydriasis, feeble light reaction, enormous disc oedema with dilatation of veins and narrowing of arteries. She had but one lumbar puncture with the evacuation of 15 cubic centimetres of fluid. Improvement set in the following day, and at the end of a week the vision was normal and the oedema had disappeared.

It is true that lumbar puncture was not the only treatment employed, but it is to this and this alone that the author attributes the results. Mercury and other drugs (dioradin, gomenol, guaiacol) were used, and in the second case tuberculin was tried with somewhat alarming effect. The author holds that lumbar puncture should be used in meningitic and post-meningitic cases, and that in tumour cases it should be given the chance of success before resorting to the more severe methods of decompression.

ERNEST THOMSON.

(3) - Majewski, Casimir (Cracow).-Some simplified procedures in orbitoplasty and fornicoplasty. (Quelques procédés simplifiés d'orbitoplastie et de fornicoplastie.) Rev. générale d'Ophtal., February, I920.

(3) The principal interest in Majewski's article seems to centre round his description of a simple method of deepening a fornix 
which has become too small to accommodate a prothesis. For the rest the article is taken up mainly with a description of all the numerous disheartening difficulties which beset the path of the surgeon who has to deal with a contracted or distorted socket, more especially of the type resulting from war injuries. Special reference is also made to the method of Verhoeff, adopted by the author, of preventing renewed cicatricial contraction after extirpation of cicatricial tissue in the operation for contracted socket. Verhoeff employs a large dermo-epidermic graft wrapped round a glass ball, placing the epidermis next the ball and the raw surface next the dissected orbital tissue. He then makes use of the resistance of the ball to exert pressure of the graft against the orbital tissue.

With regard to the method of fornicoplasty which Majewski himself describes and illustrates very clearly; this consists in making an incision from one angle of the lower eyelid conjunctiva to the other at about 8 to $10 \mathrm{~mm}$. from the margin. After dissecting the conjunctiva the knife is plunged deeply into the subjacent tissue, which is incised in its whole length almost to the lower orbital margin. No tissue is excised. By means of strong sutures the conjunctiva is then drawn down into the wound after the manner of Snellen's suture for ectropion and the sutures tied over a roll of cotton on the skin surface. The result is a new cul-de-sac which is lined by the conjunctiva on its anterior face, the posterior face being necessarily a raw surface. The number of sutures required depends upon whether the fornix is wholly or only partially obliterated.

Mutatis mutandis the author operates in the same manner where the upper fornix is concerned. Sometimes a double fornicoplasty is called for.

Majewski's article is well written and will repay perusal in the original.

ERNEST THOMSON.

\section{BOOK NOTICE}

Chirurgie de l'Oeil et de ses Annexes. Par F. TERrien, Professeur agrégé à la Faculté de Médecine de Paris. Deuxième édition augmentée et entièrement refondue. Paris : Masson et Cie. 1921. 50 francs.

During the nineteen years which have elapsed since the publication of the first edition of this book, many notable advances 